\title{
A COMPLEXIDADE DISCURSIVA NA INTERNET
}

\section{DISCURSIVE COMPLEXITY ON THE INTERNET}

Diana Luz PESSOA De BARROS*

RESUMO: Neste artigo, o objetivo é apontar, na perspectiva da semiótica discursiva, algumas particularidades dos discursos na internet em geral, principalmente em relação a quatro questões principais: a definição desses discursos quanto às modalidades falada e escrita; a organização enunciativa e veridictória dos discursos na internet, de que decorrem as especificidades da "autoria" e do "anonimato" e o caráter público e privado desses discursos. Com o exame proposto, pudemos indicar algumas das principais características dos discursos na internet: exacerbação da intensidade na interação e da extensão na duração e alcance desses discursos, devido à sua complexidade, entre a fala e a escrita; negação da oposição entre público e privado, em decorrência da formação do complexo público/privado; instalação do sujeito discursivo como homem público, embora anônimo, do ponto de vista da "autoria" do ator da enunciação; e também como sujeito confiável, pois apresenta a verdade e o saber, mas sem responsabilidade sobre o que diz, e como sujeito do poder. Complexidade, no

\footnotetext{
* Docente da UPM - Universidade Presbiteriana Mackenzie e da USP - Universidade de São Paulo.

E-mail: dianaluz@usp.br .
} 
sentido semiótico do termo, parece ser o elemento definidor dos discursos da internet.

PALAVRAS-CHAVE: Semiótica discursiva. Discurso na internet. Fala e escrita. Enunciação e veridicção. Público e privado. Autoria e anonimato.

ABSTRACT: This paper aims to indicate, according to the perspective of discursive-semiotics, some particularities of internet discourses in general, focusing on four main questions: the definition of these discourses, regarding written and spoken modalities of language; the enunciative and veridictory organization of internet discourses, from which derive the specific matters of "authorship" and "anonymity", and the public and private characters of these discourses. Having carried out the exam as proposed, we were able to define some of the main characteristics of internet discourses: exacerbation of the interaction intensity and the extension of duration and reach of these discourses, due to their complexity, between spoken and written language; negation of the opposition between private and public, as a consequence of public/private complex creation; the discursive subject establishment as a public person, although anonymous, from the enunciation actor's viewpoint of "authorship"; and also as a reliable subject, since he presents the truth and the knowledge, but free of responsibility for what is said, and as subject of power. Complexity, in its semiotic sense, seems to be the defining notion of internet discourses.

KEYWORDS: Discursive semiotics. Internet discourse. Spoken and Written language. Enunciation and Veridiction. Public and private. Authorship and anonymity. 
Este estudo reúne algumas reflexões sobre o discurso na internet, decorrentes, no primeiro momento, de nosso interesse em examinar os discursos intolerantes na internet. Constitui uma espécie de protocolo de intenções de um projeto em desenvolvimento sobre essas questões. 0 objetivo é apontar algumas particularidades dos discursos, na internet em geral, principalmente em relação a quatro aspectos principais: a definição desses discursos quanto às modalidades falada e escrita, e a seus efeitos de sentido na interação entre os sujeitos envolvidos na comunicação; a organização enunciativa e veridictória dos discursos na internet, sobretudo nas redes sociais, de que decorrem as especificidades da "autoria" e do "anonimato" e o caráter público e privado desses discursos.

Organizamos este artigo em duas partes: na primeira, apresentamos as características dos discursos na internet quanto às modalidades falada e escrita; na segunda, sua definição em relação à organização enunciativa e veridictória.

\section{As características dos discursos na internet quanto às modalidades falada e escrita}

No texto Entre a fala e a escrita: algumas reflexões sobre as posições intermediárias (BARROS, 2000), apontamos as dificuldades de se fazer uma distinção rígida entre escrita e fala e a existência de certa continuidade e de posições intermediárias entre os pontos extremos em que se caracterizam idealmente língua falada e língua escrita. Os textos da internet exemplificaram boa parte desses pontos intermediários entre fala e escrita ideais, nos três aspectos observados no estudo mencionado: as características temporais, espaciais e actoriais do discurso falado e escrito. 
Em relação ao tempo, foram examinados três traços da fala e da escrita, decorrentes da concomitância ou não concomitância da elaboração (planejamento) e da produção do discurso, e da aspectualização do tempo como contínuo (durativo) ou descontínuo (pontual). Idealmente, a escrita é planejada antes de sua realização, não apresenta, por isso mesmo, marcas de formulação e de reformulação, e suas unidades duram mais do ponto de vista da dimensão e da complexidade; a fala não é planejada antecipadamente e, por essa razão, apresenta traços de formulação e de reelaboração, e ocorre fragmentada em jatos ou borbotões. Por essas razões, a fala produz, em geral, os efeitos de sentido de informalidade (decorrentes da falta de planejamento e do oferecimento de pistas de sua elaboração e de suas revisões) e de incompletude (o texto vai sendo construído na interação como algo passageiro, que não se conserva), e a escrita, os efeitos contrários de formalidade e acabamento ou completude (BARROS, 2006; 2011).

Os textos na internet ocupam posições temporais sempre intermediárias entre os pontos extremos da fala e da escrita ideais, pois ora se aproximam da caracterização temporal ideal da fala, como nos bate-papos por computador, que não são planejados antecipadamente, apresentam traços de reelaboração e são fragmentados, ora da escrita, como na troca de e-mails, em que, em geral, não há concomitância temporal, nem marcas de formulação. Dessa forma, os textos da internet do tipo bate-papo produzem aproximadamente os mesmos efeitos que os da fala, e os das trocas de e-mails, mais próximos da escrita, são considerados formais ou informais, menos ou mais acabados, mas não tão completos quanto a escrita ideal.

Os efeitos de sentido temporais da fala e da escrita são determinados positiva ou negativamente. Assim, a informalidade e a incompletude da fala podem ser valorizadas positivamente, 
pois constroem discursos mais francos, sinceros, subjetivos, cúmplices, atuais, novos, verdadeiros, ou negativamente, porque produzem discursos com envolvimento excessivo, incompletos, mal elaborados, efêmeros. A formalidade e a completude dos discursos da escrita, por sua vez, fazem que eles sejam considerados mais objetivos, completos e bem elaborados e acabados ou excessivamente formais e rígidos. Os discursos na internet têm os atributos da fala e da escrita com as valorizações positivas e negativas de ambos.

Em relação ao espaço, a fala é caracterizada pelo efeito de sentido de presença, em um mesmo espaço, dos sujeitos envolvidos na conversação, que, dessa forma, partilham o mesmo contexto situacional. Já no texto escrito, o destinador e o destinatário não criam o efeito de se encontrarem em um mesmo espaço. Decorrem da definição espacial ideal de fala e escrita os efeitos de sentido de proximidade e de distanciamento, que também podem ser valorizados positivamente como cumplicidade, envolvimento afetivo, emocional e corporal, no caso da fala, e como afastamento objetivo e racional, no da escrita. A valoração negativa atribui à fala excesso de intimidade e falta de objetividade, e à escrita, ausência de cumplicidade, de subjetividade e de envolvimento. Duas questões se apresentam na internet, em relação ao espaço: a presença dos interlocutores e do contexto pode ser dada por duas ordens sensoriais, a visual e a auditiva, mas não pelas demais (tátil, gustativa e olfativa); a internet cria a presença virtual dos interlocutores (e do contexto), que estão na mesma sala de bate-papo, que estão online, que entram e saem da sala, que mostram o espaço em que estão (Skype etc.). Essa virtualidade de espaço tem sido apontada por neurocientistas como substituindo a presença real, ou seja, como produzindo os mesmos efeitos de presença, muito embora os efeitos de 
proximidade e envolvimento da fala sejam, nesse caso, combinados com certo distanciamento e objetividade da escrita.

Em relação ao ator, termo empregado pela semiótica para tratar dos sujeitos que assumem papéis na organização narrativa do discurso, que são investidos pela categoria linguística de pessoa e preenchidos por temas e figuras da semântica discursiva, foram examinados os papéis narrativos, temáticos e figurativos que esses atores assumem nos textos falados e escritos. Nessa perspectiva, a fala, em sua realização ideal, produz o efeito de uma conversação construída coletivamente por falante e ouvinte, com alternância desses papéis. 0 texto escrito pleno, por sua vez, constrói o efeito de elaboração individual do escritor, sem alternância dos papéis de escritor e leitor. Os efeitos de sentido decorrentes dos da organização dos atores na fala e na escrita são, principalmente, a descontração, a cumplicidade, a simetria e a reciprocidade entre interlocutores, no texto falado, em oposição à formalidade e à assimetria dos sujeitos da escrita. Esses efeitos são, também, valorizados positiva ou negativamente nos diferentes discursos. Na comunicação na internet, predominam, em relação ao ator, os mesmos efeitos de alternância de papéis e reciprocidade entre os interlocutores, próprios da fala ideal, apesar das marcas de escrita já mencionadas.

Os efeitos de sentido temporais, espaciais e actoriais dos textos falados e escritos são, para a fala, os efeitos de proximidade, subjetividade, descontração, informalidade, incompletude, simetria, reciprocidade, cumplicidade, e, para a escrita, os de distanciamento, formalidade, completude, assimetria, afastamento. Esses efeitos de sentido têm valorações positivas ou negativas nos diferentes textos.

Como os discursos na Internet ocupam posição intermediária entre a fala e a escrita, podemos caracterizá-los como um 
complexo, tanto fala, quanto escrita. 0 termo complexo foi tratado por Greimas em seus primeiros estudos de semiótica, mas não teve grande desenvolvimento posterior. Foi retomado, com muito sucesso, mais recentemente, nos trabalhos de Claude Zilberberg (2004, 2006a, 2006b). Definida pela complexidade, a comunicação na internet é, ao mesmo tempo, próxima e distante; descontraída e formal; incompleta e completa; subjetiva e objetiva. Nesse caso, ela tem seus sentidos exacerbados, já que engloba as possibilidades de interação das duas modalidades, de que resultam sua interatividade intensa, a longa conservação de seus conteúdos e a grande extensão de seu alcance. Os estudos de tensividade (FONTANILLE; ZILBERBERG, 2001; ZILBERBERG, 2006a e 2006b) permitem dizer que os discursos na internet dão maior tonicidade a algumas características da fala, mais intensa do que a escrita, como no caso da interatividade, e, ao mesmo tempo, aumentam a extensão da escrita, que dura mais, que não é passageira como a fala, e estendem, assim, seu alcance comunicacional. A Folha de S. Paulo, em $1^{\text {o }}$ de dezembro de 2013, ao apresentar, de forma didática, os riscos da internet, diz, por exemplo, entre outras informações, que "na internet tudo é para sempre". Em síntese, a interatividade exacerbada, a longa duração ou permanência dos discursos e a grande extensão de seu alcance comunicacional são as características de base dos discursos na internet, decorrentes, principalmente, da complexidade entre a fala e a escrita, mas também de outras formações de termos complexos, como veremos no próximo item.

Um bom exemplo da complexidade entre a fala e a escrita é o do jornal online. Nele, a notícia dada é, constantemente, atualizada, sempre que reformulações forem necessárias: assim, em um acidente ou catástrofe, no mesmo texto vai sendo corrigido o número de mortos e feridos; em um crime, acres- 
centam-se novos dados das vítimas e dos criminosos; em um evento, alteram-se os participantes e o público, apagando-se as informações anteriores. Em outras palavras, tal como na escrita, a formulação e a reformulação não deixam marcas no texto final refeito e, tal como na fala, as diferentes versões, conservadas no texto geral online que as integra, explicitam as correções, paráfrases e repetições do processo de reformulação textual.

A questão teórica que se coloca nessa caracterização dos discursos da internet é que os traços apontados para a língua e a fala ideais se distinguem por contrariedade (objetivo vs. subjetivo; formal vs. informal; próximo vs. distante etc.) e não admitem, portanto, conjunção. A conjunção não é possível entre termos contrários, nos discursos implicativos ou causais, como são os examinados. No entanto, se a conjunção é inadmissível ou impossível entre termos contrários, nos discursos implicativos ou causais, ela pode ocorrer, segundo Zilberberg (2004), nos discursos concessivos, que transformam o impossível em possível, e que se qualificam como "heroico, superlativo e excitante". Os discursos na internet operam, assim, a conjunção concessiva entre contrários, de que resulta o termo complexo: fala (próxima, descontraída, incompleta, subjetiva), embora escrita (distante, formal, completa, objetiva), ou escrita, embora fala. Esse discurso "heroico, superlativo e excitante" é também mítico, na definição de Claude Lévi-Strauss, ou seja, discurso de conciliação de divindade e humanidade.

Zilberberg retoma, para essas propostas, indicações de Greimas $(1975 ; 2008)$ sobre os termos complexos, abandonadas nos estudos posteriores. Para Greimas, o termo complexo não pode ser entendido como a conjunção de contrários, mas sim como sua disjunção inclusiva ou soma lógica, pois os termos contrários se relacionam por incompatibilidade e não admitem conjunção. Os estudos de Greimas dialogam com os 
do linguista dinamarquês Viggo Brøndal (1943; 1966).

Segundo Brøndal (1966), seis é o maior número de termos que o espírito humano pode apreender simultaneamente. Dessa forma, um sistema de caráter elementar será constituído, a seu ver, por, no máximo, seis termos. Além dos termos contrários, Brøndal considera necessário admitir um termo neutro e um termo complexo. 0 termo complexo, que aqui nos interessa, "será definido sendo tanto negativo quanto positivo"1 (BRØNDAL, 1966, p. 140, tradução nossa) e exemplificado, na morfologia, com o optativo, entre os modos (que reúne os caracteres opostos do imperativo e do subjuntivo) ou com o dual, entre os números (que concilia os atributos de singular e plural). É de Brøndal também a proposta de termos complexos "desequilibrados", que explicariam a possibilidade de inversão da concessão, tal como apontada nos discursos da internet. Aos quatro termos já mencionados (dois contrários, um neutro e um complexo), o linguista acrescenta mais dois, quando considera que a relação entre os termos, no complexo, pode ser de equilíbrio ou de dominância. Nos complexos desequilibrados, predomina um dos termos reunidos. A partir de Brøndal, Greimas e Courtés (2008, p. 65) propõem também dois tipos de complexo, o positivo e o negativo, "conforme a dominância de um dos dois termos contrários que entram na sua composição". É o que parece ocorrer no discurso na internet, que ora é mais fala, embora sem deixar de ser também escrita, ora é principalmente escrita, mesmo mantendo atributos da fala.

Deve-se considerar ainda que se não são as mesmas as funções históricas e sociais da fala e da escrita, tendo em vista as diferentes características das duas modalidades, tampouco

1 "sera défini par le fait d'être à la fois négatif et positif" (BRØNDAL, 1966, p. 140). 
são iguais as funções históricas e sociais da comunicação na internet, já que se define pela complexidade entre os dois extremos idealmente elaborados da fala e da escrita.

\section{Organização enunciativa e veridictória dos discursos na internet}

A segunda questão é a da organização enunciativa e veridictória dos discursos na internet, a partir de que se pode dizer alguma coisa sobre a interpretação dos discursos como verdade ou falsidade, sobre os problemas de autoria e anonimato e sobre o caráter público e privado desses discursos.

Na veridicção, as relações modais entre o ser e o parecer, que determinam os discursos como verdadeiros, mentirosos, secretos ou falsos, e levam seus destinatários a neles acreditar ou não, têm na internet características próprias. Se os textos de histórias de pescador são, por definição, interpretados como falsos, isto é, que nem parecem nem são verdadeiros, os da internet são, em geral, considerados verdadeiros, ou seja, que parecem e são verdadeiros, e, mais do que isso, que eles são discursos que desmascaram a mentira, que parece, mas não é verdadeira, ou revelam o segredo, que não parece, mas é verdadeiro. A interpretação como discurso verdadeiro e também o desmascaramento da mentira e a revelação do segredo decorrem do efeito de sentido de grande quantidade de saber armazenado pela internet e do de interatividade acentuada. 0 destinador desses discursos é colocado na posição de sujeito do saber e seu destinatário, devido à interatividade intensa já mencionada, deles se considera, em boa parte, também como autor-destinador. Esse destinatário, assim construído, acredita e confia nos discursos que também são seus. 
O anonimato é, sem dúvida, um dos traços que caracterizam o discurso na internet e está relacionado à questão da autoria, e, portanto, à organização da enunciação do discurso. Seu estudo se faz de dois modos: pela reconstrução da organização sintático-narrativa da enunciação; pela construção semântica do ator da enunciação, a partir principalmente do exame dos temas e figuras do discurso e das relações intertextuais e interdiscursivas. Para a construção do efeito de autoria, e, consequentemente, também de anonimato, são usados nos discursos procedimentos sintáticos e semânticos.

As estratégias da sintaxe, no caso da autoria e do anonimato que nos interessam, dizem respeito ao emprego das categorias enunciativas de pessoa (FIORIN, 1996) e, também, às relações narratológicas que se estabelecem entre enunciador e enunciatário. Com o emprego das categorias enunciativas de pessoa são produzidos nos discursos efeitos de aproximação da enunciação, devido ao uso, em geral, do eu discursivo, ou de distanciamento da enunciação, com o emprego, principalmente, do ele do discurso (ver, a esse respeito, FIORIN, 1996, BARROS, 2000 e 2002). Os discursos na internet empregam predominantemente o "eu-aqui-agora" da enunciação enunciada, que, em princípio, deveria produzir efeito de autoria. 0 efeito de autoria precisa, porém, ser completado pelos procedimentos semânticos da enunciação, pois o sujeito da enunciação é construído, sintaticamente, como actante da enunciação e, semanticamente, como ator da enunciação:

Do ponto de vista da produção do discurso, pode-se distinguir o sujeito da enunciação, que é um actante implícito, logicamente pressuposto pelo enunciado, do ator da enunciação: neste último caso, o ator será, digamos, "Baudelaire", enquanto se define pela totalidade de seus discursos (GREIMAS; COURTÉS, 2008, p. 45). 
Em outras palavras, o sujeito da enunciação se define também pelos papéis que assume no espetáculo enunciativo e, dessa forma, ao construir seu texto, constrói-se como uma posição sintática e como um ator da enunciação, com identidade, estilo e corpo, preenchido por crenças e valores, modos de ser e de fazer, decorrentes de papéis temáticos e figurativos (DISCINI, 2003). A semiótica desenvolveu, na semântica do discurso, os conceitos de tematização e de figurativização: os temas, abstratos, disseminam-se pelo texto em percursos que, por sua vez, podem ser concretizados sensorialmente pelo procedimento de figurativização. Os temas e figuras são determinados sócio-historicamente e asseguram o caráter ideológico desses discursos (FIORIN, 1988, p. 1-19). Os temas e figuras, dessa forma, trazem ao ator da enunciação as marcas de sua inserção sócio histórica e ideológica, e, além disso, como as figuras investem sensorialmente os temas, dão-lhe corpo. 0 exame dos atores da enunciação é, portanto, o modo como os estudos semióticos procuram dar à enunciação identidade corporal e sócio histórica.

Finalmente, para a determinação desse ator da enunciação, é preciso considerar ainda as relações entre discursos, que permitem diferenciar o ator da enunciação do ator da narração. A identidade do narrador, definida por um único discurso, distingue-se da do enunciador, caracterizada por um conjunto ou uma totalidade de discursos, conforme aparece na citação de Greimas e Courtés, acima exposta.

Retomando a questão do efeito de autoria nos discursos da internet, se o efeito de autoria plena resulta dos dois procedimentos, do sintático e do semântico, no caso da internet, os recursos semânticos, principalmente o da figurativização do ator da enunciação, parecem caminhar na direção contrária da 
que tomam os procedimentos sintáticos. Se, nos discursos na internet, os procedimentos sintáticos criam a ilusão de aproximação e subjetividade, na semântica discursiva, os temas são, em geral, figurativizados com o recurso principal dos pseudônimos, mas nem sempre ocorre a figurativização exacerbada ou iconização com o nome próprio e outras formas de concretização, o que conduziria à formação de totalidades discursivas e à construção plena do ator da enunciação. Disso decorre o anonimato, que permite a construção do sujeito da enunciação e, até mesmo, do ator-narrador, que é uma voz delegada pelo enunciador, mas não a do ator da enunciação pleno. Resulta daí o efeito de sentido de irresponsabilidade, moralizada negativamente pela sociedade. A irresponsabilidade é, nesse caso, definida como agir, sem os riscos de sanção de suas ações. 0 dicionário define irresponsável como aquele que não pode ser responsabilizado pelos atos que pratica, no caso da internet, devido ao uso da estratégia discursiva de apagamento de algumas partes ou aspectos do ator da enunciação, tornando-o anônimo.

É o que ocorre, por exemplo, em textos sobre a questão passional da vingança e, sobretudo, a da hoje chamada vingança pornô, e nos do aplicativo Lulu (o dos homens se chama Tubby e surgiu depois do Lulu), em que mulheres avaliam o perfil de homens, atribuindo-lhes notas e comentários, indexando os homens com hashtags como "\#maisbaratoquepãonachapa, \#piormassagemdomundo, \#curteoromerobritto, \#apaixonadopelaex". Uma das decorrências do aplicativo Lulu foi a resposta dada por um grupo de quatro empresários que usou o mesmo procedimento de anonimato e conseguiu 1 milhão de reais com o serviço Lulu Fake: o serviço cobra $\mathrm{R} \$ 24,90$ por avaliações artificiais no aplicativo, e, em apenas 5 dias, 2000 homens pagaram para ter uma melhor avaliação no Lulu (Folha de S. Paulo, 5 de dezembro de 2013, mercado 2, p.4). 
Outro bom exemplo é o da chantagem pela internet, que também depende do anonimato:

\section{Imagem 1 - Chantagem envolvendo jogadores do futebol britânico}

Homem ameaça revelar fotos íntimas de jogadores da Inglaterra. Chantagista está prometendo tumultuar ambiente ao revelar fotos e vídeos dos jogadores nus.

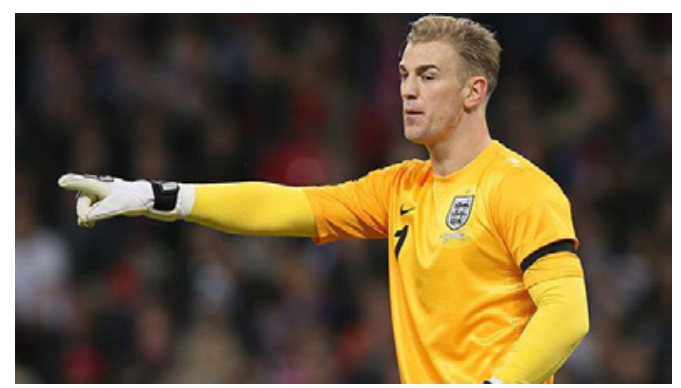

Goleiro Joe Hart é um dos alvos de chantagem

O tabloide britânico "Daily Star" revelou uma chantagem inusitada com os atletas da seleção da Inglaterra. Um homem está prometendo causar confusão no ambiente da equipe ao revelar fotos íntimas dos jogadores e começa a causar preocupação às portas da Copa do Mundo.

0 maluco, identificado pelo perfil @Sportsmennude5 no Twitter, alega ter contatado diretamente estrelas do time como o goleiro Hart e o atacante Sturridge, ameaçando revelar material de foto e vídeo que expõe os jogadores nus nos vestiários.

Fonte: jornalcentralbrasil.blogspot.com.br ${ }^{2}$

2 Disponível em: «http://jornalcentralbrasil.blogspot.com.br/2014/05/homem-ameaca-revelar-fotos-intimas-de.html . Acesso em: 12 dez. 2015. 
Se o anonimato na internet é, em geral, relacionado à irresponsabilidade e à covardia, e moralizado negativamente pela sociedade, também se estabelecem laços entre o anonimato e a diversão. 0 anonimato de artistas e escritores sempre existiu, por razões diversas, entre as quais a de causar prazer, ao se colocar no percurso temático da diversão, do entretenimento. A história de Hansky, em texto do New York Times, (encarte da Folha de S. Paulo de 29 de abril de 2014, p.1), exemplifica bem essa relação na internet. Hansky, artista de Nova Iorque, que fundiu, em um muro, grafites do artista britânico Bansky com o rosto de Tom Hanks, mandou uma foto de sua obra para um site especializado em arte de rua e obteve, com isso, enorme sucesso na internet, várias exposições e venda de obras. Para criar e manter esse sucesso, uma das estratégias por ele usadas foi esconder da imprensa sua verdadeira identidade: "Há um pouco mais de fascínio ou empolgação quando esse véu de anonimato está no ar. Quero continuar anônimo e me divertir com isso".

0 anonimato, irresponsável e/ou divertido, diz respeito, portanto, à questão de autoria, mas está ele também relacionado à distinção entre público e privado. Tudo indica que, tal como ocorreu em relação às modalidades falada e escrita, o discurso da internet define-se pelo termo complexo privado e público, ou seja, pela ruptura da oposição entre privado e público. 0 domínio do público é regulamentado pela lei, pela regra, o do privado é o das variações e preferências individuais. Na internet, preferências individuais, próprias da privacidade do sujeito, são expostas e submetidas às leis públicas ou se tornam regras públicas. Daí as humilhações e suicídios das jovens expostas na vingança pornô e a preocupação em monitorar a imagem e a reputação do sujeito na internet. Essa 
continuidade entre o público e o privado é, provavelmente, resultante das características já apontadas do discurso da internet: o sujeito do discurso da internet é instalado como um sujeito do poder que a interatividade intensificada, a extensão e propagação alargadas, o saber e o anonimato lhe dão. Dotado de poder, ele se coloca como um homem público, mas anônimo, daí o paradoxo, que pode, sem riscos, expor suas preferências, sentimentos e emoções privadas e fazer delas regras públicas. Dessa forma, o discurso na internet define-se também como um complexo embora privado, público, ou, com inversão de equilíbrio, embora público, privado. Ao qual se acrescenta o paradoxo de sujeito construído como um homem público, mas anônimo.

Em síntese, algumas das principais características dos discursos na internet são: exacerbação da intensidade na interação e da extensão na duração e alcance desses discursos (devido à sua complexidade, entre a fala e a escrita); negação da oposição entre público e privado (devido à formação do complexo público/privado); instalação do sujeito discursivo como homem público, embora anônimo, do ponto de vista da autoria do ator da enunciação; e também como sujeito confiável, pois apresenta a verdade e o saber, mas sem responsabilidade sobre o que diz, e como sujeito, portanto, do poder. Complexidade, no sentido semiótico do termo, parece ser o elemento definidor dos discursos da internet. Foram aqui apontadas algumas dessas formações de termos complexos, em geral, desequilibrados. É preciso pensar em outras, como, por exemplo, a das multibreagens, proposta por Sandro Tôrres de Azevedo, para o exame de ações publicitárias que utilizam recursos tecnológicos de realidade aumentada (comunicação no simpósio "O discurso na internet", no $2^{\circ}$ Congresso Nacional Mackenzie “Letr@s em rede. Tradição e inovação", 2015). 
O sociólogo espanhol José Castells, ao tratar, em entrevista, da agressividade na internet brasileira, disse:

A imagem mítica do brasileiro simpático existe só no samba. Na relação entre as pessoas, sempre foi violento. A sociedade brasileira não é simpática, é uma sociedade que se mata. Esse é o Brasil que vemos hoje na internet (Folha de S. Paulo, 18 de maio de 2015, A12)

Estudiosos brasileiros, como Marilena Chauí e José Luiz Fiorin, em estudos diversos, já haviam apontado essa falsa imagem construída da cordialidade do brasileiro, desmascarada, segundo Castells nos discursos da internet, que expõem a violência e os preconceitos da sociedade. A internet não é a causa do preconceito e da intolerância, mas os discursos nela construídos, pelas características discursivas apontadas, facilitam, desencadeiam, incentivam ou escancaram a produção de discursos agressivos, intolerantes e preconceituosos e sua intensa e extensa divulgação.

\section{REFERÊNCIAS}

BARROS, D. L. P. Entre a fala e a escrita: algumas reflexões sobre as posições intermediárias. In: PRETI, D. Fala e escrita em questão. São Paulo: Humanitas, 2000. p. 57-77.

BARROS, D. L. P. Interação em anúncios publicitários. In: PRETI, D. Interação na fala e escrita. São Paulo: Humanitas, 2002. p. 17-44.

BARROS, D. L. P. Efeitos de oralidade no texto escrito. In: PRETI, D. Oralidade em diferentes discursos. São Paulo: 
Humanitas, 2006. p. 57-84.

BARROS, D. L. P. Efeitos da oralidade em gêneros discursivos diferentes. In: PRETI, D. (Org.). Variações na fala e na escrita. São Paulo: Humanitas, 2011. v. 11, p. 209-242.

BRØNDAL, V. Essais de linguistique générale. Copenhagen: Munksgaard, 1943.

BRØNDAL, V. Structure et variabilité des systèmes morphologiques. In: HAMP, E. (Org.). Readings in Linguistics II. Chicago: The University of Chicago Press, 1966. p.139-146.

DISCINI, N. 0 estilo nos textos. São Paulo: Contexto, 2003.

FIORIN, J. L. Linguagem e ideologia. São Paulo: Ática, 1988.

FIORIN, J. L. As astúcias da enunciação. São Paulo: Ática, 1996.

FONTANILLE, J.; ZILBERBERG, C. Tensão e significação. Trad. Ivã Carlos Lopes; Luiz Tatit e Waldir Beividas. São Paulo: Discurso Editorial/Humanitas, 2001.

GREIMAS, A. J. Sobre o sentido: ensaios semióticos. Trad. Ana Cristina Cruz Cezar et al. Petrópolis: Vozes, 1975.

GREIMAS, A. J.; COURTÉS J. Dicionário de Semiótica. Trad. Alceu Dias Lima et al. São Paulo: Contexto, 2008.

ZILBERBERG, C. As condições semióticas da mestiçagem. In: 
CAÑIZAL, E. P.; CAETANO, K. E. (Org.). 0 olhar à deriva: mídia, significação e cultura. São Paulo: Annablume, 2004.

ZILBERBERG, C. Éléments de grammaire tensive. Limoges: Pulim, 2006a.

ZILBERBERG, C. Síntese da gramática tensiva. Significação, São Paulo, n. 25, p. 163-204, jun, 2006b.

Artigo recebido em setembro de 2015 e aprovado em novembro de 2015.

Disponível em: http://seer.fclar.unesp.br/casa 